\title{
A COMPARATIVE STUDY OF EFFECT OF INJECTION MORPHINE SULPHATE AND MORPHINE PLUS DEXMEDETOMIDINE IN INTRAVENOUS PATIENT-CONTROLLED ANALGESIA IN PATIENTS UNDERGOING TOTAL ABDOMINAL HYSTERECTOMY
}

\author{
Rajat Jain ${ }^{1}$,Eeshwar Rao Madishetti², Robin Kumar Cintury³ \\ ${ }_{1}^{1}$ Assistant Professor, Department of Anaesthesiology, IQ City Medical College, Durgapur. \\ ${ }^{2}$ Assistant Professor, Department of Anaesthesiology, Chalmeda Anand Rao Institute of Medical Sciences (CAIMS), Karimnagar. \\ ${ }^{3}$ Assistant Professor, Department of Anaesthesiology, Sikkim Manipal Institute of Medical Sciences, Gangtok.
}

\section{ABSTRACT}

\section{BACKGROUND}

Abdominal hysterectomy is a common gynaecological surgery usually performed under general anaesthesia and is associated with significantly painful postoperative stress thereby requiring sufficient analgesia. Opioids are frequently used in the postoperative period, but their use is accompanied with many undesirable side effects. A multimodal approach using different classes of analgesics or using patient-controlled analgesia (PCA) significantly minimises undesirable dose related effects and improves side effect profile for opioids.

This study aims to investigate if the use of a continuous dexmedetomidine infusion with intravenous (IV) Morphine PCA improves postoperative analgesia and reduces opioid consumption and opioid-related side effects.

\section{MATERIALS AND METHODS}

This randomised double blinded study was carried out with sixty female patients with ASA physical status I-II of age group 18 to 65 years scheduled for elective total abdominal hysterectomy under general anaesthesia selected randomly and divided into two groups of 30 each. Group-I received opioid analgesia and Group-II received a combination of dexmedetomidine and opioid analgesia. Cumulative PCA requirements, pain intensities, cardiovascular, respiratory variables, PCA related adverse events and rescue drugs administered were recorded and statistically analysed for 24 hours post-operation. Patient satisfaction level was assessed by a polar questionnaire.

\section{RESULTS}

Study group II required $16.02 \%$ less morphine and this dose reduction was statistically highly significant ( $<<0.0001)$. Group II had greater fall in mean arterial pressure $(\mathrm{p}<0.0001)$ after transient rise in MAP (for few hours after extubation) and slow heart rate compared to group I. Whereas level of sedation between two groups were similar after 4 hours of extubation. Right from the beginning of IV PCA, at each observational time point, oxygen saturation was significantly higher in group-II. Time taken to reach VRS $\leq 4$ was shorter in group-II compared to group-I ( 2 hours vs. 4 hours $p<0.0001$ ) and VRS remained low consistently ( $<<0.0001$ ) at each observational time point. The 4- to 24-hour incidence of nausea, vomiting and pruritus was significantly lower in Group II, $3 \%, 1 \%, 0 \%$ vs. $11 \%, 8 \%$ and $6 \%(\mathrm{p}<0.05)$. Bradycardia and hypotension was observed among Group II patients but they responded quickly to a single dose atropine and fluid bolus.

\section{CONCLUSION}

The addition of dexmedetomidine to IV PCA morphine resulted in superior analgesia, significant morphine sparing, less morphineinduced nausea, vomiting and was devoid of additional sedation or untoward haemodynamic changes. Greater overall patient satisfaction was observed with dexmedetomidine-morphine PCA.

\section{KEYWORDS}

Analgesia, Patient-Controlled Analgesia, Dexmedetomidine, Morphine.

HOW TO CITE THIS ARTICLE: Jain R, Madishetti ER, Cintury RK, et al. A comparative study of effect of injection morphine sulphate and morphine plus dexmedetomidine in intravenous patient-controlled analgesia in patients undergoing total abdominal hysterectomy. J. Evolution Med. Dent. Sci. 2017;6(23):1905-1909, DOI: 10.14260/Jemds/2017/418

\section{BACKGROUND}

International Association for the Study of Pain (IASP) defines pain as "An unpleasant sensory and emotional experience

Financial or Other, Competing Interest: None.

Submission 07-02-2017, Peer Review 03-03-2017,

Acceptance 11-03-2017, Published 20-03-2017.

Corresponding Author:

Dr. Rajat Jain

Department of Anaesthesiology,

JD Block-3, 1st Floor, Flat No. 31-B,

IQ City Medical College, Sovapur, Bijra Road,

Jemua, Durgapur, West Bengal-713206

E-mail: rajatjain1981@hotmail.com

DOI: $10.14260 /$ jemds $/ 2017 / 418$ associated with either actual or potential tissue damage or described in terms of such damage." Abdominal Hysterectomy is a common gynaecological surgery usually done under general anaesthesia and is associated with significantly painful postoperative stress thereby requiring analgesia.

The practice of using opioids in the postoperative period is often accompanied by undesirable side effects. Therefore, various opioid adjunct analgesics have been used to minimise the undesirable dose related effects and improve the side effect profile of opioids. $(1,2,3)$

Dexmedetomidine is an alpha ${ }_{2}$-adrenergic agonist with sedative and analgesic properties. It is 8 times more specific for $\alpha 2$ receptors in comparison with clonidine ${ }^{(4,5)}$ and inhibits 
the release of norepinephrine.(6,7) Postsynaptic activation of $\alpha 2$ receptors in the central nervous system inhibits the sympathetic activity and decreases the blood pressure and heart rate. Thereby produces analgesia, sedation, and anxiolysis.(8)

Intravenous PCA for pain management is gaining worldwide popularity and can be conveniently administered solely when the patient activates the system by requesting a demand dose after an established lockout period or administered in conjunction with a basal rate infusion depending upon the patient's need. It minimises episodes of analgesic gaps and negative feedback loop developed between patient demand and level of analgesia. $(9,10)$

The present randomised, controlled prospective study aims to compare the haemodynamic stability, sedation scores and morphine consumption among patients on morphine analgesia in comparison with morphine plus dexmedetomidine IV- PCA in post TAH patients.

\section{MATERIALS AND METHODS}

This randomised double blinded study was carried out with sixty female patients with ASA physical status I - II of age group 18-65 years included in the study. Patients on clonidine/beta-blockers/antidepressants, those with Bradycardia $(\mathrm{HR}<50)$, Arrhythmias, Hypertension, Ischaemic Heart Disease (IHD), Conduction block, Underlying GI diseases, Previous history of Post-Operative Nausea, Vomiting (PONV) and motion sickness were excluded from the study.

A detailed history was taken and thorough systemic examination of all subjects included in the study was performed. ECG, Chest X-ray, Complete blood and urine analysis inclusive of renal function and blood glucose analysis of all subjects were recorded preoperatively. Informed consent was taken from all patients included in the study.

The study population was divided into two groups $(n=30)$ by computer-generated double blinding randomisation.(11) All 60 subjects underwent TAH under general anaesthesia. (Induction: Fentanyl \& Propofol $2 \mathrm{mg} / \mathrm{kg}$, Atracurium 0.5 $\mathrm{mg} / \mathrm{kg}$; Maintenance: Isoflurane with Nitrous oxide and Oxygen in ratio of 60:40 along with titrated dose of atracurium). Post-reversal (using Neostigmine $0.04 \mathrm{mg} / \mathrm{kg}$ and Glycopyrrolate $0.004 \mathrm{mg} / \mathrm{kg}$ ), the general condition of the subjects was assessed by Verbal Rating Score (VRS). For VRS $\geq 5$, titrated PCA solution IV $2 \mathrm{~mL}$ at interval of 5 minutes was given until VRS reached $\leq 4$. After which patients were encouraged to self-administer their own PCA with a setting of $2 \mathrm{~mL}$ bolus and 10-minute lockout time. PCA was instituted by double blinding using PCA reservoir cassette $100 \mathrm{~mL}$ capacity (CADD-PRIZM 51553) with particular identification numbers. The blinding code was retained by the nursing staff and opened only after completion of study. For the reason of patient safety, a sealed envelope containing treatment assignment for unexpected serious adverse events was kept in PACU and ward.

Group I (Control group) received $90 \mathrm{~mL}$ solution of $45 \mathrm{mg}$ Morphine in $0.9 \%$ Normal saline (each $\mathrm{mL}$ containing $0.5 \mathrm{mg}$ of morphine).

Group II received $90 \mathrm{~mL}$ solution of $45 \mathrm{mg}$ Morphine plus $360 \mu$ of dexmedetomidine in $0.9 \%$ Normal saline (each $\mathrm{mL}$ containing $0.5 \mathrm{mg}$ morphine and $4 \mu \mathrm{g}$ of dexmedetomidine).

Monitoring of haemodynamic profile and level of sedation was done at specific time points $(0,0.5,1,2,3,4,6,12,18$ \& 24 Hours). Total time to reach VRS $\leq 4$, total morphine at VRS 4 , total morphine consumption in 24 hours, incidence of side effects and rescue drugs given in each group were recorded. If the VRS resting $>4$ during 4-24 hours after operation or if patients required more than three administrations of rescue medication for nausea, vomiting, bradycardia and pruritus, then it was considered as PCA treatment failure.

Any patient with hypotension ( $>20 \%$ decrease in Mean Arterial Pressure from pre-surgery baseline), Level of sedation $>4$ and respiratory depression (Respiratory rate $<8$ bpm) lasting $>10$ minutes was considered as severe adverse event and if so occurred PCA was withheld and patient was considered for appropriate treatment. Atropine, Ondansetron and Diphenhydramine were the main rescue drugs supplied as per patients' requirements.

Statistical analysis was done by chi-square test and student t-test. P-value of $<0.05$ was considered significant and P-value of $<0.001$ was considered highly significant.

\section{RESULTS}

Present study was designed to study the effectiveness of morphine PCA (Group-I) in comparison with morphine plus dexmedetomidine PCA (Group II). The mean age and weight of the study population did not show any statistically significant difference between the two groups.

The fall in the heart rate 30 minutes post initiation of analgesia was greater among Group II patients (morphine and dexmedetomidine) with a mean difference of $6.73 \%$ from the baseline in comparison with Group I patients (morphine) with a mean difference of $1.95 \%$ from the baseline. Group II was found to have slower heart rate at all points of time in comparison with Group I as depicted in Figure/Table -1.

From the zeroth hour throughout the study period the mean oxygen saturation of Group II was better maintained in comparison to Group I as depicted in Figure/Table-2. Mean arterial pressure (MAP) showed a progressive fall in Group I with the maximum fall recorded at 3 hours post initiation of PCA. Comparatively Group II patients showed increase in MAP and the values remained higher than the baseline value as depicted in Figure/Table-3. The changes in the mean systolic pressure (SBP) and mean diastolic blood pressure (DBP) were in sync with the MAP changes up to 3 hours postoperatively. After which Group-II (Morphine plus Dexmedetomidine) showed lower SBP and DBP in comparison to group-I (Morphine) as depicted in Figure/ Table- 4 and Figure/ Table- 5 respectively.

Group I patients took about 4 hours to reach a VRS $\leq 4$ in comparison Group II patients took about 2 hours to reach VRS $\leq 4$. Data analysis suggests that the VRS scores of Group II patients remained consistently low at all observational time points $(\mathrm{p}<0.0001)$ as depicted in Figure/Table- 6 .

The mean dose of morphine consumed by Group I patients to reach VRS $\leq 4$ was $12.63 \mathrm{mg} \pm 1.25 \mathrm{SD}$. Morphine consumed by Group II patients to reach VRS $\leq 4$ was 10.38 $\mathrm{mg} \pm 1.33 \mathrm{SD}$. The mean morphine consumption at 24 hours was significantly higher among Group I patients in comparison with Group II patients as depicted in Figure/Table-7. Group II patients showed significantly lesser side effects in comparison with group I patients as depicted in Figure/ Table-8. 


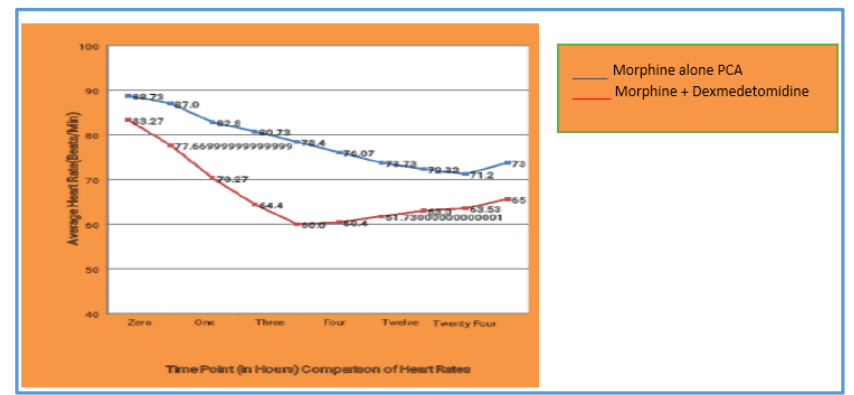

Graph 1. Variation of Heart Rate over Time after Initiation of Analgesia

\begin{tabular}{|c|c|c|c|c|c|c|}
\hline \multirow[b]{3}{*}{ Time } & \multicolumn{4}{|c|}{$\mathrm{SPO}_{2}$ (Percent at 21 Lit.) } & \multirow{2}{*}{\multicolumn{2}{|c|}{ T- Test }} \\
\hline & \multicolumn{2}{|c|}{ Group - I } & \multicolumn{2}{|c|}{ Group- II } & & \\
\hline & Mean \pm SD & (\%)Diff. & Mean \pm SD & (\%)Diff. & t-Value & P-Value \\
\hline Zero Hour & $98.53 \pm 0.94$ & --- & $99.13 \pm 0.63$ & --- & -1.936 & 0.0577 \\
\hline After Half an Hour & $97.10 \pm 0.88$ & -1.45 & $99.00 \pm 0.59$ & -0.13 & 9.449 & $<0.0001^{*}$ \\
\hline After 1 Hour & $96.63 \pm 0.93$ & -1.93 & $98.70 \pm 0.82$ & -0.44 & 8.855 & $<0.0001^{*}$ \\
\hline After 2 Hours & $96.27 \pm 0.94$ & -2.30 & $97.90 \pm 0.61$ & -0.91 & 80606 & $<0.0001^{*}$ \\
\hline After 3 Hours & $96.30 \pm 0.88$ & -2.27 & $97.33 \pm 0.80$ & -1.24 & 8.185 & $<0.0001^{*}$ \\
\hline After 4 Hours & $96.00 \pm 0.74$ & -2.57 & $97.30 \pm 0.70$ & -1.51 & 8.647 & $<0.0001^{*}$ \\
\hline After 6 Hours & $96.07 \pm 0.58$ & -2.50 & $97.37 \pm 0.49$ & -1.82 & 6.984 & $<0.0001^{*}$ \\
\hline After 12 Hours & $96.20 \pm 0.66$ & -2.37 & $97.30 \pm 0.70$ & -1.85 & 6.262 & $<0.0001^{*}$ \\
\hline After 18 Hours & $96.47 \pm 0.73$ & -2.10 & $97.37 \pm 0.49$ & -1.78 & 5.607 & $<0.0001^{*}$ \\
\hline After 24 Hours & $96.67 \pm 0.76$ & -1.89 & $97.67 \pm 0.48$ & -1.48 & 6.093 & $<0.0001^{*}$ \\
\hline
\end{tabular}

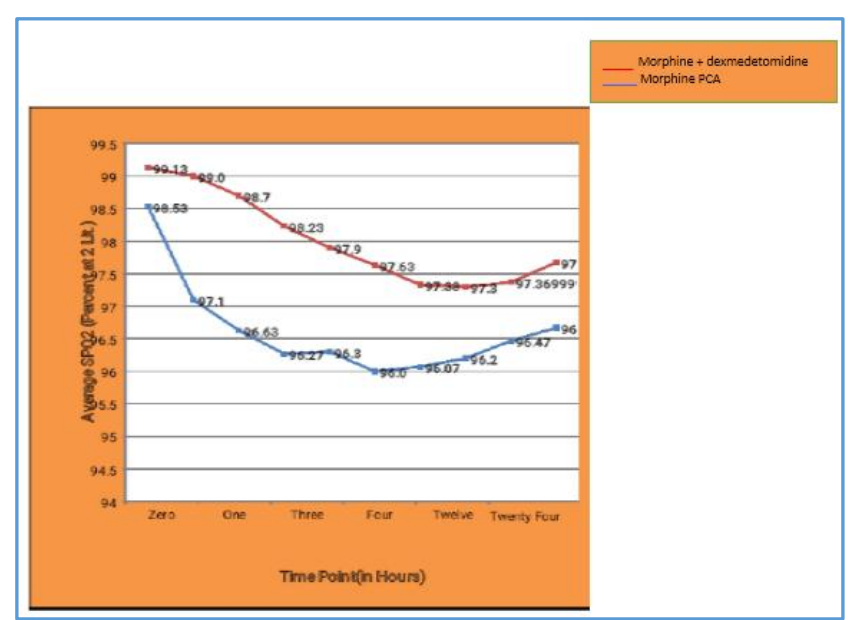

Graph 2. Comparison of Mean Arterial Pressure at Different Time Intervals

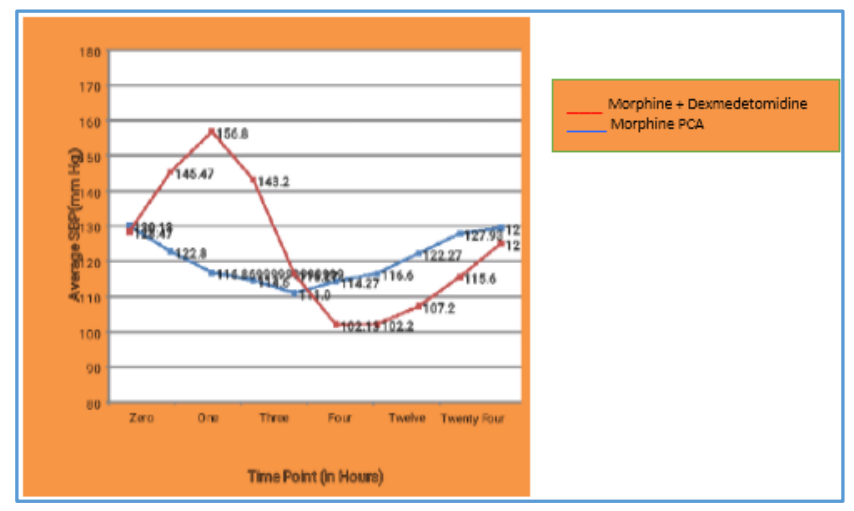

Graph 3. Comparison of Systolic Blood Pressure

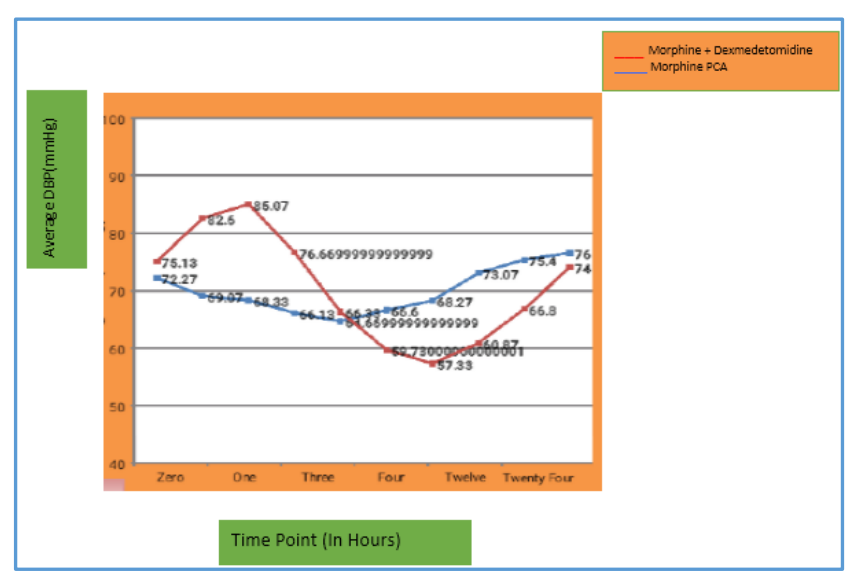

Graph 4. Comparison of Diastolic Blood Pressure

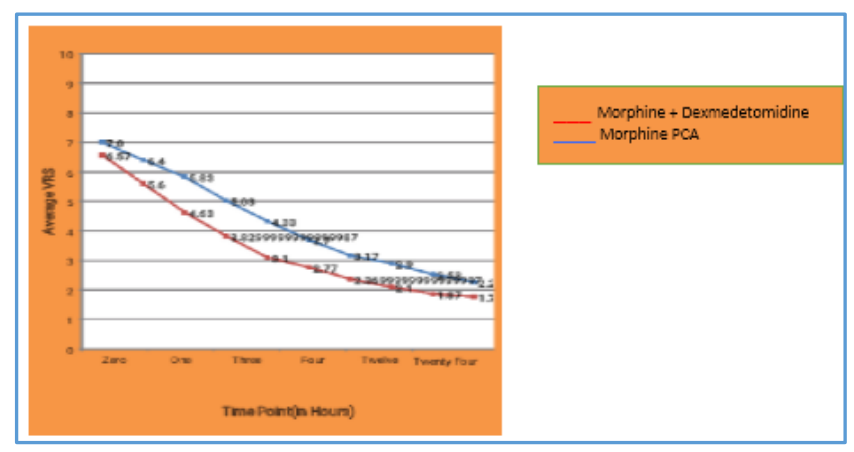

Graph 5. Comparison of VRS Scores 


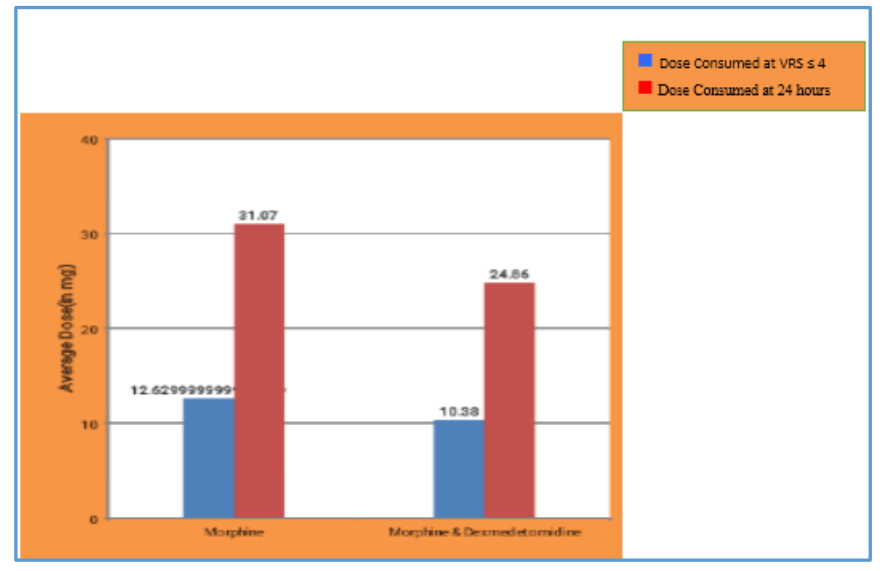

Graph 6 Analysis of Dose Consumption

\begin{tabular}{|c|c|c|c|}
\hline & $\begin{array}{c}\text { Morphine } \\
\text { Group (I) }\end{array}$ & $\begin{array}{c}\text { Morphine \& } \\
\text { Dexmedetomidine } \\
\text { Group (II) }\end{array}$ & $\begin{array}{c}\text { P } \\
\text { Value }\end{array}$ \\
\hline $\begin{array}{c}\text { Nausea N } \\
(\%)\end{array}$ & $\begin{array}{c}11 \\
(36.67 \%)\end{array}$ & $3(10.00 \%)$ & $0.03^{*}$ \\
\hline Vomiting & $8(26.67 \%)$ & $1(3.33 \%)$ & $0.0300^{*}$ \\
\hline Pruritis & $6(20.00 \%)$ & $0(0.00 \%)$ & $0.0314^{*}$ \\
\hline \multicolumn{3}{|c|}{ Table 2. Comparison of Side Effects } \\
\hline
\end{tabular}

*Statistically Significant; Independent sample tests for proportion are performed.

Statistically Significant if P-value $<0.05$.

\section{DISCUSSION}

Present study showed that patients receiving dexmedetomidine-morphine mixture (Group II) required $16.02 \%(\mathrm{P}<0.0001)$ less morphine. These findings were comparable with studies by Unlugenc et al that showed Dexmedetomidine-morphine mixture significantly enhanced the analgesic effect of morphine, reduced PCA morphine requirements and achieved significantly greater pain relief in comparison to solitary morphine.(12,13) Percentage of dose reduction in the present study was less when compared to dose reduction documented in studies by Lin TF, and Yeh YC et al. (14) Agonism at $\alpha 2$-adrenoceptors in the spinal cord and in the locus coeruleus produces analgesia and sedation, respectively. (15) In the presence of these effects, it is difficult to distinguish whether analgesic or sedative effects are responsible for the reduced opioid requirements. In this study, higher level of sedation at 3 and 4 hours (with $p$ $<0.0001$ and 0.0088 ) was recorded after which no statically significant difference in sedation scores was noted. This might be due to synergistic effect of residual anaesthetics. Higher oxygen saturation in Group II was noted with maximum fall in saturation of $1.85 \%$ vs. $2.57 \%$ from baseline, compared to morphine alone PCA which can be explained by reduced ventilatory depression in Group II. $(8,16)$

In our study, Group II patients reached the target VRS score 2 hours faster compared to Group I ( $p<0.0001)$. It was also found that VRS was consistently significantly lower in Group II throughout the study compared to Group I $(\mathrm{p}<0.0001)$.

Thus, reduction of stress, attenuation of affectivemotivational component (unpleasantness) of pain, analgesic and sedative actions are likely to account for the morphine sparing effect of dexmedetomidine. $(17,18)$

Present study showed the following haemodynamic changes, after initial rise in MAP in Group II in comparison to Group I, there was more reduction in mean arterial pressure, systolic/diastolic blood pressure and heart rate in Group II patients. Though there was $>20 \%$ fall in mean arterial pressure from baseline in Group II $(\mathrm{p}<0.0001)$ it was transient and these patients responded to fluid infusion. This figure is similar compared to other cited articles.(19,20) Haemodynamic changes after dexmedetomidine administration are complex, one of the known effects following rapid administration of dexmedetomidine is an activation of $\alpha 2$ receptors on vascular smooth muscle, which results in transient vasoconstriction, increase in MAP, and presumably reflex decrease in heart rate. Fall in the heart rate was noted in patients on dexmedetomidine; however, they responded quickly to a single dose of atropine. After the initial effect of dexmedetomidine a more gradual central effect becomes apparent including sedation, which might be due to the decrease in sympathetic outflow, circulating catecholamine level and the direct peripheral dilation caused by morphine.

The reduction in the incidence and severity of nausea, vomiting and pruritus was noted on combining dexmedetomidine and morphine in PCA due to reduced consumption of morphine. Treatment of the morphine related side effects with opioid antagonists (E.g. Naloxone) was avoided because they bring about a reversal of opioid analgesia. Urinary retention due to morphine was not considered as patients were catheterised.

This study also supports the fact that the synergistic effect of dexmedetomidine-morphine mixture reduces morphine consumption while improving the quality of analgesia, \& reduces opioid-related side effects. Decreased pain intensities together with the decrease in PCA morphine requirements results in reduced nausea induced by morphine and greater overall patient satisfaction with PCA.

\section{Limitation of the Study}

The influence of residual anaesthesia on haemodynamic profile and level of sedation during the postoperative period was not evaluated.

\section{CONCLUSION}

Total abdominal hysterectomy is associated with moderate/severe postoperative pain. Opioids are often necessary for analgesia, and patients are thereby subjected to opioid associated side effects. However, multimodal analgesia using dexmedetomidine achieves better pain control along with additive benefits such as reducing the dose of opioid consumption and reducing opioid associated side effects.

\section{REFERENCES}

[1] White PF, Kehlet H. Improving postoperative pain management: what are the unresolved issues. Anaesthesiology 2010;112(1):220-5.

[2] Kehlet H, Wilmore DW. Multimodal strategies to improve surgical outcome. Am J Surg 2002;183(6):630-41. 
[3] Remy C, Marret E, Bonnet F. Effects of acetaminophen on morphine side-effects and consumption after major surgery: meta-analysis of randomized controlled trials. Br J Anaesth 2005;94(4):505-13.

[4] Venn RM, Karol MD, Grounds RM. Pharmacokinetics of dexmedetomidine infusions for sedation of postoperative patients requiring intensive caret. $\mathrm{Br} \mathrm{J}$ Anaesth 2002;88(5):669-75.

[5] Virtanen R, Savola JM, Saano V, et al. Characterization of the selectivity, specificity and potency of medetomidine as an alpha 2-adrenoceptor agonist. Eur J Pharmacol 1998;150(1-2):9-14.

[6] Venn RM, Grounds RM. Comparison between dexmedetomidine and propofol for sedation in the intensive care unit: patient and clinician perceptions. Br J Anaesth 2001;87(5):684-90.

[7] Martin E, Ramsay G, Mantz J, et al. The role of the alpha2-adrenoceptor agonist dexmedetomidine in postsurgical sedation in the intensive care unit. J Intensive Care Med 2003;18(1):29-41.

[8] Shapiro A, Zohar E, Zaslansky R, et al. The frequency and timing of respiratory depression in 1524 postoperative patients treated with systemic or neuraxial morphine. J Clin Anesth 2005;17(7):537-42.

[9] Viscusi ER. Patients-controlled drug delivery for acute postoperative pain management a review of current and emerging technologies. Reg Anesth Pain Med 2008;33(2):147-58.

[10] White PF. Use of patient-controlled analgesia for management of acute pain. JAMA 1988;259(2):243-7.

[11] Dallal GE. Randomization generator 2013. Available from: 〈http://www.randomization.com〉

[12] Unlugenc H, Gunduz M, Guler T, et al. The effect of preanaesthetic administration of intravenous dexmedetomidine on postoperative pain in patients receiving patient-controlled morphine. Eur J Anaesthesiol 2005;22(5):386-91.
[13] Khan ZP, Ferguson CN, Jones RM. Alpha-2 and imidazoline receptor agonists. Their pharmacology and therapeutic role. Anaesthesia 1999;54(2):146-65.

[14] Lin TF, Yeh YC, Yen YH, et al. Antiemetic and analgesic sparing effects of diphenhydramine added to morphine intravenous patient-controlled analgesia. $\mathrm{Br}$ J Anesth 2005;94(6):835-9.

[15] Noorizan AA, Chue MC, Yong CY, et al. Efficacy and safety of dexmedetomidine versus morphine in postoperative cardiac surgery patients. Int J Clin Pharm 2011;33(2):150-4.

[16] Ko S, Goldstein DH, Kerkhof VEG. Definitions of respiratory depression with intrathecal morphine postoperative analgesia: a review of the literature. Can J Anaesth 2003;50(7):679-88.

[17] Abdelmalak B, Makary L, Hoban J, et al. Dexmedetomidine as sole sedative for awake intubation in management of the critical airway. J Clin Anesth 2007;19(5):370-3.

[18] Hunter JC, Fontana DJ, Hedley LR, et al. Assessment of the role of alpha 2-adrenoceptor subtypes in the antinociceptive, sedative and hypothermic action of dexmedetomidine in transgenic mice. Br J Pharmacol 1997;122(7):1339-44.

[19] Grossman M, Abiose A, Tangphao O, et al. Morphineinduced venodilation in humans. Clin Pharm Ther 1996;60(5):554-60.

[20] Ebert TJ, Hall JE, Barney JA, et al. The effects of increasing plasma concentrations of dexmedetomidine in humans. Anesthesiology 2000;93(2):382-94. 